\section{Monte Carlo Simulation for Economic Analysis of Hydropower Pumped Storage Project in Nepal}

Kaspar Vereide, Leif Lia and Lars Ødegård

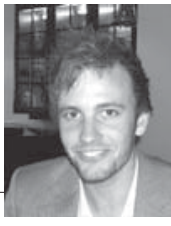

Kaspar Vereide

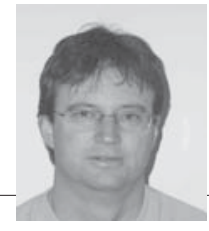

Leif Lia

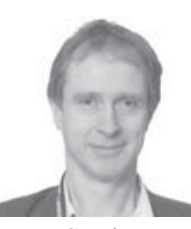

Lars Ødegård

Abstract: Investments in hydropower pumped storage projects (PSP) are subjected to a high degree of uncertainty. In addition to normal uncertainties in hydropower schemes, the profit of a pumped storage scheme is dependent on the margin between power prices for buying and selling, which is difficult to predict without a power purchase agreement (PPA).

A PSP without a PPA and without known construction costs requires quantification of the uncertainties in order to make qualified decisions before investing in such projects. This article demonstrates the advantages of using Monte Carlo (MC) simulations as a tool in the economic analysis of PSPs. The method has been tested on a case study, namely the Tamakoshi-3 Hydropower Project (HPP) in Nepal.

The MC method is used to calculate the probability distribution of the net present value of installing reversible units in the Tamakoshi-3 HPP. The calculations show that PSPs may be profitable in Nepal, given a beneficial development of the power market.

The MC method is considered to be a useful tool for economic analysis of PSPs. In this case study of installing reversible units in the Tamakoshi-3 HPP, there are many uncertainties, which the MC simulation method is able to quantify.

Key words: Hydropower, pumped storage, reversible turbines, Monte Carlo, Tamakoshi-3, Nepal

\section{Introduction}

A ll over the world, except in regions with many regulated reservoirs such as Norway, hydropower pumped storage projects (PSP) are commonly used to supply the grid with peaking power and power in periods with scarce power production (Deane et al 2010). PSPs are most frequently used in regions where the thermal power is dominating in the supply system. So far no PSPs are commissioned or under construction in Nepal. A PSP may be designed for several purposes:

- Seasonal pumping of water from low level reservoirs to high level reservoirs in periods with high run off. The stored water may be used in dry seasons.

- Daily peaking operation by subsequently producing in peak periods and pumping in off peak periods.

- Controlling frequency and voltage in the grid. Regarding to the different purposes listed above, a PSP will be designed accordingly. In many countries such as Germany, Austria, Switzerland and Norway, new PSPs are developed and constructed. It is one of the most promising technologies to handle the future challenges in the electricity supply system.

Due to the deficit of electrical power in Nepal, numerous new hydropower projects (HPP) have to be commissioned in order to meet the demand (NEA 2012). For HPPs with reservoirs in both the upstream and downstream end, there is an opportunity to install one or more units for pumping. The most recent technology available is reversible turbines, which eliminate the need for separate units for pumping and generation.

Investments in PSPs are subject to a high degree of uncertainty. In addition to normal uncertainties in hydropower schemes, the profit of a pumped storage scheme is dependent on the margin between power prices for buying and selling, which is difficult to predict without a power purchase agreement (PPA). This margin is often referred to as the spread. Compensation for auxiliary services such as stabilizing the frequency and voltage introduce additional uncertainties but these are disregarded in this article due to lack of a commercial market for such services in Nepal.

A PSP without a PPA and without known construction costs requires quantification of the uncertainties in order to make qualified decisions before investing in such projects. This article demonstrates the advantages of using Monte Carlo (MC) simulations as a tool in the economic analysis of PSPs. The method has been tested on a case study, namely the Tamakoshi-3 HPP in Nepal. The MC simulation method is used to calculate the probability distribution of the net present value (NPV) of installing reversible units in the Tamakoshi-3 HPP.

The NPV is a frequently used parameter for evaluating the economic feasibility of hydropower projects. It is calculated as the sum of each annual cash flow, discounted for required rate of return. The following equation presents the calculation where $\mathrm{i}=$ rate of return, $\mathrm{N}=$ economical lifetime, $\mathrm{Rt}=$ annual net cash flow, $t=$ year number (Khan et al 1993):

$$
N P V(i, N)=\sum_{t=0}^{N} \frac{R_{t}}{(1+i)^{t}}
$$

This article is written to highlight the possibility of using MC simulations for economic analysis of PSPs, and the reader needs to be aware that the performed calculations are based on beneficial prerequisites. The downstream reservoir is assumed to be available without cost. Tamakoshi-3 HPP has been shown to be most profitable with only one reservoir, one power plant and construction of a longer headrace tunnel (SN Power 2010). This will eliminate the possibility of having reservoirs both in the upstream and downstream 
end, and thus eliminating the possibility of installing reversible units.

The main reason for considering two power plants and two reservoirs is to reduce risk in the project. The project is still economically feasible, but will be constructed in smaller steps. The performed calculations evaluate whether reversible units should be included in the design if two reservoirs are available.

\section{Case Study - Tamakoshi-3 Hydropower Project}

Tamakoshi-3 is one of the future HPPs in Nepal, and is currently being considered as a potential investment for the Norwegian Power Company SN Power. With the design presented in Figure 1 and Figure 2 (edited from SN Power, 2010), reversible units can be implemented. If reversible units prove to be profitable for the Tamakoshi-3 HPP, this may imply profitability also for other projects.

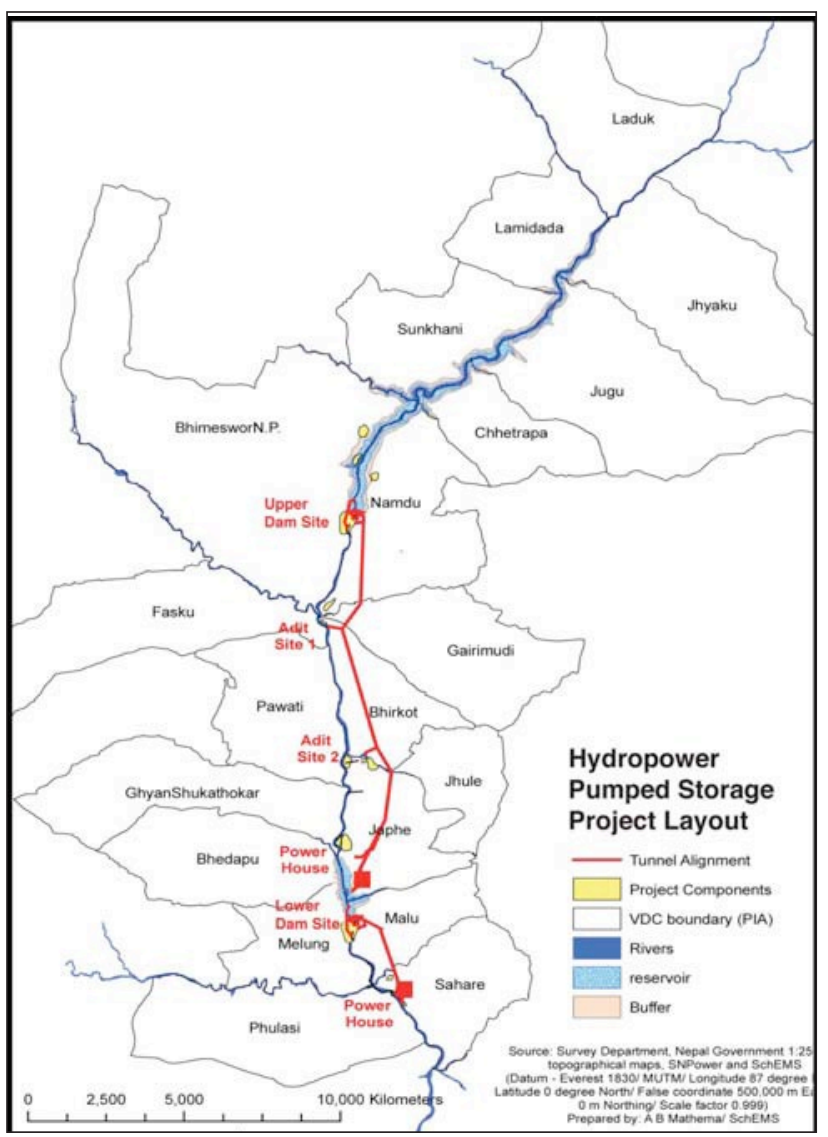

Figure 1. Tamakoshi-3 HPP Layout (Edited from SN Power 2010).

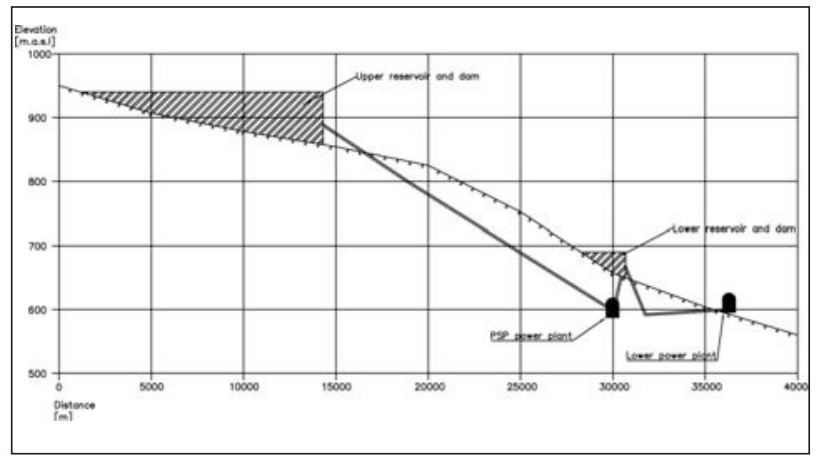

Figure 2. Profile Plot of Tamakoshi-3 HPP.
Data on the Nepalese power market and power supply system has been given by the Nepalese Department of Electricity Development (DOED). Data on the Tamakoshi -3 HPP has been given by SN Power.

SN Power has been considering several project layouts for the Tamakoshi-3 HPP. In the layout presented in this article, the project design includes two reservoirs and two power plants. Reversible units are implemented in the upstream power plant. Key features for the upstream power plant of the Tamakoshi-3 HPP are presented in Table 1 (SN Power 2010).

\begin{tabular}{|l|c|c|}
\hline \multicolumn{3}{|c|}{ Upstream Reservoir } \\
\hline HRW & 940 & m.a.s.l. \\
\hline LRW & 890 & m.a.s.l. \\
\hline Live storage & 137 & mill. $\mathrm{m}^{3}$ \\
\hline \multicolumn{3}{|c|}{ Wownstream Reservoir } \\
\hline HRW & 690 & m.a.s.l. \\
\hline LRW & 670 & m.a.s.l. \\
\hline Live storage & 14 & mill. $\mathrm{m}^{3}$ \\
\hline \multicolumn{3}{|c|}{} \\
\hline Total tunnel length & 13000 & $\mathrm{~m}$ \\
\hline Tunnel cross section area & 74 & $\mathrm{~m}^{2}$ \\
\hline Gross headloss & 16 & $\mathrm{~m}$ \\
\hline \multicolumn{3}{|c|}{ Power station } \\
\hline Gross head & 250 & $\mathrm{~m}$ \\
\hline Maximum discharge & 305 & $\mathrm{~m}^{3} / \mathrm{s}$ \\
\hline Number of units & 3 & \\
\hline Turbine unit rating & 206 & $\mathrm{MW}$ \\
\hline
\end{tabular}

Table 1. Upstream Power Plant.

The reservoir volumes are too small for seasonal storage and the PSP will be used uniquely for daily peaking operation, based on the spread between peak and off peak power price. Auxiliary services such as regulation of frequency and voltage have been disregarded in this article, since there is no commercial market for these.

\section{Monte Carlo Simulation Model}

The MC simulation model presented in this paper is based on the works presented by Rubinstein (2008). Monte Carlo simulations for economic risk assessment for wind power are documented by Montes, Martin et al (2011) and $\mathrm{Li}, \mathrm{Lu}$ and $\mathrm{Wu}$ (2012), but similar calculations for PSPs have to the authors' knowledge not been documented earlier. The principle of the MC simulation model is:

1. The model variables are selected based on the specific influence on the profit. The numbers of variables (X) are chosen based on preferred complexity and accuracy of the analysis.

2. Each of the variables is described with a probability distribution, with a maximum, minimum and expected value.

3. In a $\mathrm{MC}$ simulation with $\mathrm{X}$ variables, $\mathrm{N}$ values are randomly drawn from each of the variables. This gives $\mathrm{N}$ sets of $\mathrm{X}$ variables.

4. These $\mathrm{N}$ sets are used to calculate construction cost 
and power production, producing $\mathrm{N}$ possible costs and $\mathrm{N}$ possible productions.

5. The $\mathrm{N}$ possible costs and productions result in $\mathrm{N}$ possible NPVs.

6. These N possible NPVs are analyzed statistically and used to describe the probability distribution of the NPV.

The result is a probability distribution of the NPV, which is used to evaluate the profitability of the PSP. In comparison to the traditional deterministic method, one number is calculated as expected NPV; the MC simulation method will provide more details for an investment decision.

It is important to have a high enough number $\mathrm{N}$, to ensure convergence of the result. However, the main challenge in MC simulation is to find the probability distributions for each of the variables. For the Tamakoshi-3 Hydropower Project in Nepal, the probability distributions are based on available data provided by the DOED and SN Power.

The transformation of the data into probability distribution is subject to individual interpretation, which may introduce inaccuracies in the result. The accuracy of this interpretation will have a direct impact on the accuracy of the result.

\section{Model Input}

In order to evaluate the NPV of installing reversible aggregates in the Tamakoshi-3 HPP, the following input variables are used:

- Future amount of peak price hours

- Future power price in Nepal

- Future power price in India

- Future electricity demand in Nepal

- Future electricity production in Nepal

- Reversible unit costs

The input variables are based on the following data received from DOED and SN Power:

- Time series of the electricity production and demand in Nepal;

- Predictions of the future production and demand in Nepal;

- Historical and current power prices in Nepal and India;

- Predictions of future electricity prices in Nepal and India;

- Power grid capacity in Nepal and India; and

- Project layout of the Tamakoshi-3 HPP.

Based on this data, the selected input variables are described with probability distributions as presented in the following sections. The probability distributions are based on the theory as presented by Walpole (2007).

The characteristics of the probability distributions such as maximum, minimum and expected values are limited by the knowledge of the authors.

\section{Peak Price Hours}

The number of hours per day when the power price is high will impact on the profit of a PSP, and has been selected as a variable in the model. In this simulation, the power price is assumed to change directly from peak to off peak without an intermittent zone. The key data of the probability distributions are presented in Table 2.

\begin{tabular}{|l|c|}
\hline \multicolumn{1}{|c|}{ Parameter } & Peak price hours \\
\hline Minimum & 0 \\
\hline Maximum & 12 \\
\hline Expected value & 5 \\
\hline Distribution & Discrete \\
\hline
\end{tabular}

Table 2. Number of Peak Price Hours.

A probability for zero peak price hours has been included, to account for the probability that the future power market does not have peak price hours. The maximum number of peak price hours is chosen as twelve due to the possibility of having twelve peak hours and twelve off peak hours. Figure 4 presents the probability distribution.

The probability distribution used to describe the number of peak price hours is discrete. This is chosen since the number is assumed to be in whole hours, and not minutes.

\section{Future Power Price in Nepal}

The variable for future power price in Nepal is the price the owner of the power plant receives per produced

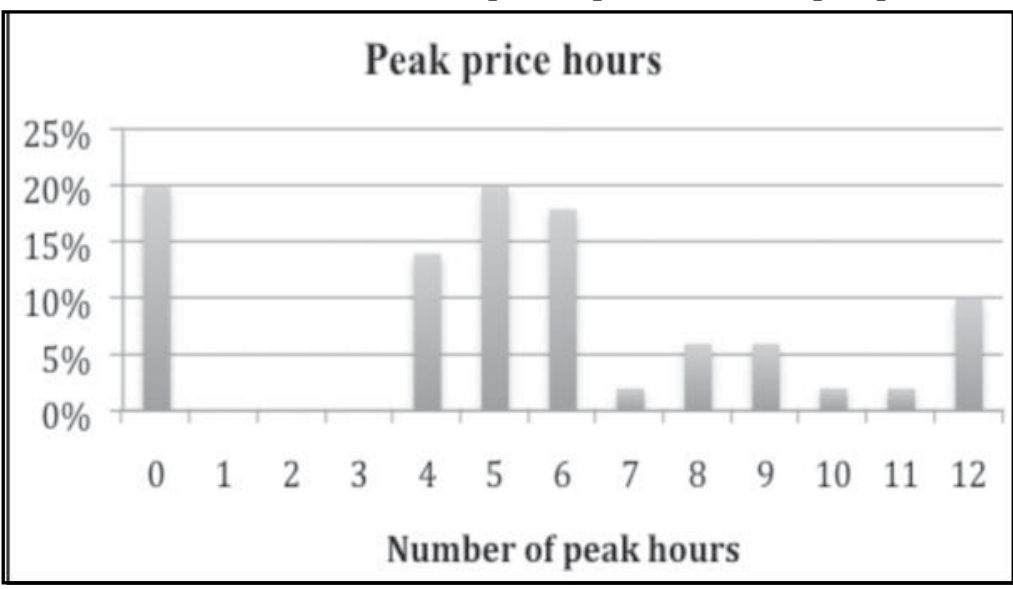

Figure 3. Probability Distribution Peak Price Hours.

MWh. The future power price has been separated into three components to describe the daily and seasonal variation:

- The base power price (wet season off peak period)

- Additional fee during dry season

- Additional fee during daily peak period

The price during the peak period in the dry season is equal to the added sum of base power price, the dry season fee and the peak period fee. The formula and key data of the probability distributions are presented in Table 3 .

\section{Future Power Price in India}

The future power price in India is predicted as monthly 


\begin{tabular}{|l|c|c|c|}
\hline Parameter & $\begin{array}{c}\text { Wet off peak } \\
\text { period price } \\
\text { USD/MWh }\end{array}$ & $\begin{array}{c}\text { Additional Dry } \\
\text { season fee } \\
\text { USD/MWh }\end{array}$ & $\begin{array}{c}\text { Additional Peak } \\
\text { period fee } \\
\text { USD/MWh }\end{array}$ \\
\hline Minimum & 55 & 41 & 27 \\
\hline Maximum & 96 & 96 & 110 \\
\hline Expected value & 68 & 48 & 55 \\
\hline Distribution & Chi squared & Exponential & Chi squared \\
\hline $\mathrm{f}(\mathrm{x})$ & $\begin{array}{l}232 \Gamma(32)(x-4000250) 32 \\
-1 e-x-4000500\end{array}$ & $17310.7 e-x 1000+30.7$ & $\left.\begin{array}{c}173125 \mathrm{~T}(5)(x- \\
2000200)\end{array}\right) 4 e-x 2$ \\
\hline
\end{tabular}

Table 3. Future Power Price in Nepal.

averages by the Spanish consultancy firm AF Mercados EMI (2011). The variable is separated in two components, deviation from the prediction and the spread. Table 4 presents the formula and key data of the probability distributions.

\begin{tabular}{|l|c|c|}
\hline \multicolumn{1}{|c|}{ Parameter } & $\begin{array}{c}\text { Deviation from } \\
\text { prediction \% }\end{array}$ & $\begin{array}{c}\text { Spread } \\
\text { USD/MWh }\end{array}$ \\
\hline Minimum & $-60 \%$ & 0 \\
\hline Maximum & $+60 \%$ & 137 \\
\hline Expected value & $0 \%$ & 48 \\
\hline Distribution & Normal & Chi squared \\
\hline $\mathrm{f}(\mathrm{x})$ & $1182 \pi e-(x) 22 * 182$ & $173129 \mathrm{C}(9)(x 200) 8 \mathrm{e}-\times 400$ \\
\hline
\end{tabular}

Table 4. Future Power Price in India.

\section{Future Power Production and Demand}

The future production and demand of electricity in Nepal will determine whether there is surplus or de in the system. This will influence whether there is power available for pumping. A prediction of future annual production and demand is supplied by the DOED.

To estimate the future production and demand, the following parameters are used:

\begin{tabular}{|c|c|c|}
\hline Parameter & Future production & Future demand \\
\hline Minimum & $-100 \%$ & $0 \%$ \\
\hline Maximum & $-20 \%$ & $90 \%$ \\
\hline Expected value & $-60 \%$ & $50 \%$ \\
\hline Distribution & Modified normal & Normal \\
\hline$f(x)$ & $0,0192 \pi e-(x-60) 22+92+0.1144 \pi e-(x-90) 22+42$ & $1232 \pi e-(x-50) 222+232$ \\
\hline
\end{tabular}

Table 5. Future Power Production and Demand.

- Deviation from the predicted annual production growth

- Deviation from the predicted annual demand growth The key data of the probability distributions is presented in Table 5 .

\begin{tabular}{|l|l|l|}
\hline Parameter & Cost & \\
\hline Turbines & 8 & mill. USD \\
\hline $\begin{array}{l}\text { Generators/ } \\
\text { control gear }\end{array}$ & 16 & mill. USD \\
\hline Sum & 24 & mill. USD \\
\hline
\end{tabular}

Table 6. Expected Cost of Three Reversible Units.

The future production depends on the amount of new power plants c o n s t r u c t e d. Today, the rate of constructing new power plants is slow, but the rate

is expected to increase in the future if projects can be made more feasible. The future production is therefore described with a modified normal distribution in order to account for both slow development and fast development.

\section{Reversible Unit Cost}

It is only the isolated cost of the reversible units that are studied in this article. The cost and profit of the original project without reversible units is disregarded. This is chosen in order to isolate the NPV of installing reversible units. Table 6 and Table 7 present the expected cost and key data of the probability distributions.

The cost for the reversible units is based on a cost estimate produced by the Norwegian Water Resources and Energy Directorate (2010). It is assumed that all the three units will be reversible.

\begin{tabular}{|l|l|}
\hline \multicolumn{1}{|c|}{ Parameter } & \multicolumn{1}{c|}{ Reversible unit cost } \\
\hline Minimum & $-20 \%$ \\
\hline Maximum & $+20 \%$ \\
\hline Expected value & $0 \%$ \\
\hline Distribution & Normal \\
\hline $\mathrm{f}(\mathrm{x})$ & \multicolumn{1}{|c|}{$1102 \pi e-(x) 22 * 102$} \\
\hline
\end{tabular}

Table 7. Probability Distribution of Reversible Unit Cost.

\section{Simulation of PSP Operation}

The random selection of $\mathrm{N}$ sets of $\mathrm{X}$ variables is performed with the Matlab software. These $\mathrm{N}$ sets are then used in a PSP operation model to calculate how the PSP plant will operate under the different conditions, and the resulting profit. Compared with the production simulation for regular hydropower plants, the PSP model needs to be programmed with a criterion for when to pump, and when to produce. The simulation model has been programmed with the Visual Basic software on an hourly resolution and is based on the following assumptions:

- No limitations in transmission capacity (only valid for limited amount of MW);

- Power may be sold in both the Nepalese and the Indian market;

- Power will be bought where it is least expensive, and sold where it is most expensive;

- No limits in the amount of energy that can be bought or sold in the Indian market;

- Pumping mode cannot operate in the wet season (4 months) due to full reservoir.

The output of the operation model is the profit from operating the reversible units. Next, the cost of the reversible units is included and the NPV of the project may be calculated.

A flow chart of the power production/pump routine in the operation model is presented in Figure $5(\mathrm{PP}=$ power price). This routine is implemented in a normal production simulation model, which calculates the operation of regular HPPs based on hydrological data and operational strategy. Hydrological data and operational strategy for the Tamakoshi-3 HPP is described in SN Power (2010).

Due to the head loss in the waterway, limited efficiency of the units and transmission losses, only approximately $65 \%$ of the energy that is used for 


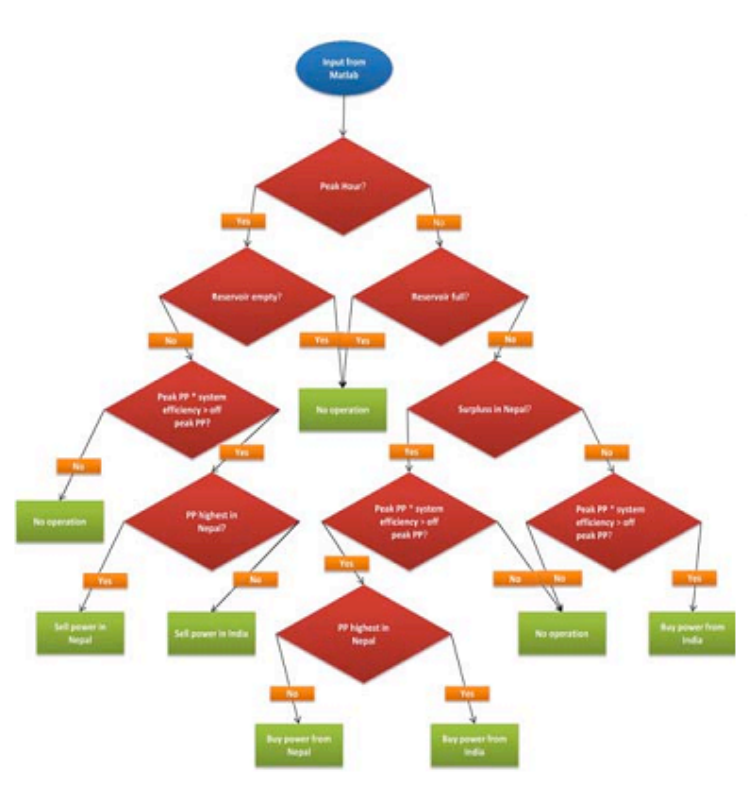

Figure 4. PSP Routine Flow Chart.

pumping will be returned when the same water is used for power production. The head loss, unit efficiency and transmission losses are defined as system efficiency in the routine, and will vary with the unit discharge. In order to profit from the operation of reversible units, the spread in the power price needs to be sufficiently high. The routine accounts for this with the requirement that the peak price multiplied with system efficiency must be higher than the off peak price in order to run the reversible units.

\section{Result}

The principle of Monte Carlo simulation relies on a high enough number of simulations in order to converge the result. Figure 6 presents a convergence test for the MC model.

Due to the computing time, it is chosen to use $\mathrm{N}=15,000$ as satisfying the convergence criteria. However, the convergence test shows that the solution has not fully converged at this number of simulations, and that there is some inaccuracy in the result. For the purpose of demonstrating the method, the convergence is regarded as sufficient.

The resulting probability distribution of the NPV is presented in Figure 7. A discount rate of $11.5 \%$ has been used. As can be seen, installation of reversible units is likely to be profitable, but there is a high standard deviance. The expected value of the NPV is 192 million USD, with a standard deviance of 201 million USD.

The output domain of the NPV is in the range e [24, 1475 million USD]. The theoretical maximum has a probability of approximately $0.00005 \%$, and is sensitive to the chosen maximum of the input parameters.

There is a large probability of negative NPV from the project. This is mainly due to the probability of zero peak price hours in Nepal, as presented in Figure 4. In addition there is a probability that the spread is too small

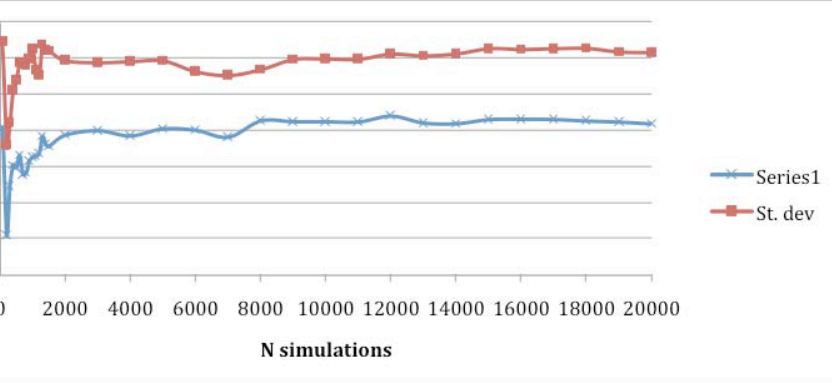

Figure 5. Convergence Test.

operate the PSP. In this case there will be no income, and the NPV will be equal to the cost of the reversible aggregates.

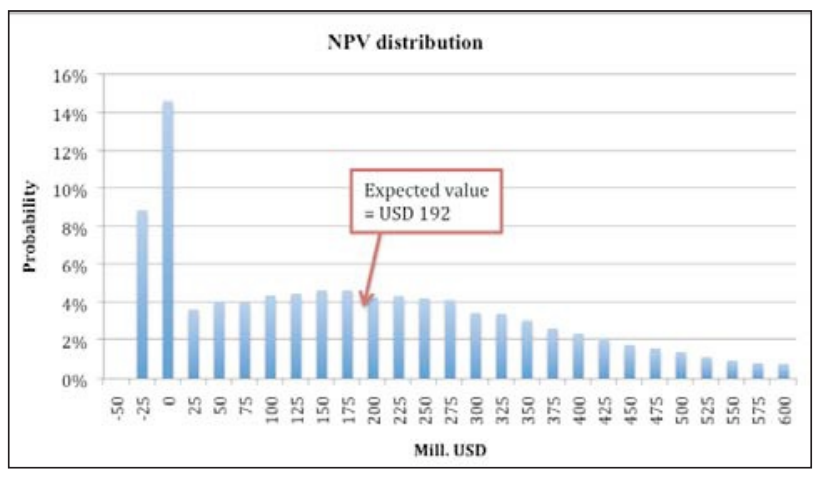

\section{Discussion}

Figur 6. NPV Distribution.

The results presented in this article are regarded as optimistic. The input data and many of the assumptions may provide unrealistically beneficial conditions for the PSP. However, the results prove that there may be a potential profitable market for reversible units in Nepal, given the possibility of operating under beneficial conditions in a combined Nepalese and Indian power market.

Considering the MC method, the negative aspect is the difficulty of accurately transforming the input data into probability distributions. In case of limited input data, personal interpretation may cause unrealistic results. Limited input data and personal interpretation are normally the main sources of error in the economic analysis. However, given accurate input data, the MC method will provide an accurate probability distribution of the output, which presents the entire output domain and gives a better understating of the possible economic scenarios of the project.

The MC method is considered to be a useful tool for economic analysis of PSPs. In the case study of a potential PSP in Nepal, there are many uncertainties, which the MC simulation is able to quantify.

Kaspar Vereide, MSc is a PhD candidate at the Norwegian University of Science and Technology (NTNU). His current research is "Long Tunnels for Hydropower Pumped Storage".

Corresponding address: Kaspar.Vereide@ntnu.no

Leif Lia, PhD, is a Professor at the Department of 
Hydraulic and Environmental Engineering at NTNU. His main expertise is hydropower engineering, and he has over 15 years of experience from the field.

Corresponding address: Leif.Lia@ntnu.no

Lars Ødegård, MSc, is a Project Director in the Norwegian Power Company SN Power.

Corresponding address: Lars.Odegard@snpower.com

\section{References}

AF-Mercados EMI, 2011, Integration of South Asian Regional Power Markets, Department of Hydropower Development Power Marked Workshop, Kathmandu.

Deane J.P., B. P. Gallachoir and E. J. McKeogh, 2010, TechnoEconomic Review of Existing and New Pumped Hydro Energy Storage Plant, Renewable and Sustainable Energy Reviews, vol. 14, issue 4, pp. 1293-1302.

Li C., G. $\mathrm{Lu}$ and S. Wu, 2012, The Investment Risk Analysis of Wind Power Project in China, Renewable Energy, vol. 50, pp. 481-487.
Montes G.M., E. P. Martin, J. A. Bayo and J. O. Garcia, 2011, The Applicability of Computer Simulation Using Monte Carlo Techniques in Wind farm Profitability Analysis, Renewable and Sustainable Energy Reviews, vol. 15, issue. 9, pp. 4746 - 4755.

Nepal Electricity Authority (NEA), 2012, Annual Report, pp. 3, URL http://nea.org.np/anual-report.html.

Norwegian Water Resource and Energy Directorate (NVE), 2010, Cost Estimate for Large Hydropower Plant, Oslo, URL http://www.nve.no/en/ Newsarchive1/News/Cost-base-for-hydropowerplants-for-downloading/.

SN Power, 2010, Main Report, Tamakoshi-3 Hydroelectric Project, Nepal.

Rubinstein R. Y. and D. P. Kroese, 2008, Simulation and the Monte Carlo Method 2nd Edition, John Wiley and Sons, New York.

Walpole R.E., R. H. Myers, S. L. Myers, K. Ye, 2007, Probability and Statistics for Engineers and Scientists 8th Edition, Pearson Prentice Hall, London, pp. 171-201.

\section{CALENDAR OF EVENTS - ENERGY}

13-15 February, 2013: Solar Power-gen Conference and Exhibition. Location: San Diego Convention Center, San Diego, CA, USA. More info: http://www. solar-powergen.com/index.html

25-26 February, 2013: Wind Power Summit Conference. Location: Dallas, TX, United States of America. More info: http://www.windpowersummit.com/el

25-26 February, 2013: 2nd Annual International Conference on Sustainable Energy and Environmental Sciences. Location: Singapore. More info: http:// www.env-energy.org/

27 February-1 March, 2013: Micro Perspectives for Decentralized Energy Supply Conference. Location: Berlin, Germany. More info: http://www. microenergysystems.tu-berlin.de/conference

27 February - 1 March, 2013: World Sustainable Energy Days. Location: Wels, Austria. Contact Email: office@esv.or.at. More info: www.wsed.at

7-9 March, 2013: International Renewable and Sustainable Energy Conference. Location: Ouarzazate, Morocco. More info: http://www.medspace.org/irsec

30 March, 2013: National Conference on Green Energy - (NCGE13). Location: Chennai, Tamilnadu, India. More info: http://www.rmd.ac.in/NCGE13/ contact.html

8 - 12 April, 2013: IEA Energy Training Week 2013. Location: Paris, France. More info: http://www.iea. org/training/etw2013/\#d.en.15745

10-12 April, 2013: Power and Energy Systems - AsiaPES Conference. Location: Phuket, Thailand. More info: http://www.iasted.org/conferences/home-8oo.html

17-18 April, 2013: Fourth Clean Energy Ministerial. Location: New Delhi, India. More info: http://www. cleanenergyministerial.org/events/cem4/index.html

23-25 April, 2013: The 6th Energy Storage Forum Europe 2013 Conference. Location: Berlin, Germany. More info: http://www.energystorageforum.com/

24-26 April 2013: Asset Management for Enhancing Energy Efficiency in Water and Wastewater Systems. Location: Marbella, Spain. More info: http:// iceam2013.es/
25-27 April, 2013: The 7th International Energy Trade Fair, RENEXPO Central Europe. Location: Budapest, Hungary. Contact: REECO Hungary Kft. Contact Email: hungary@reeco.hu. More info: www.renexpo.hu

26 April, 2013: Clean Energy Financing Forum for Central America and the Caribbean. Location: San Pedro Sula, Honduras. More info: http://cti-pfan. net/events_detail.php?eventsid $=43$

9-10 May, 2013: Energy and Environment: bringing together Economics and Engineering Conference. Location: Porto, Portugal. More info: http://www.fep.up.pt/conferences/icee/

23-25 May, 2013: The 10th International Symposium on Power of Green Energy. Location: Toruń, Poland. More info: http://gape2012.umk.pl

27 - 30 May, 2013: The Asian and Pacific Energy Forum (APEF 2013). Location: Vladivostok, Russian Federation. More info: http://www.greengrowth.org/?q=event/asianand-pacific-energy-forum-apef-2013

29-31 May, 2013: 9th See Congress and Exhibition on Energy Efficiency and Renewable Energy (EE \& RE). Location: Sofia, Bulgaria. More info: http://www. eeandres.viaexpo.com/en/congress

30-31 May, 2013: International Conference on Alternative Energy in Developing Countries and Emerging Economies. Location: Bangkok, Thailand. More info: http://www.sci.tsu.ac.th/2013aedcee/

6-9 June, 2013: ACSEE 2013 - The Third Asian Conference on Sustainability, Energy and the Environment Conference. Location: Osaka, Japan. More info: http://acsee.iafor.org

19-21 June, 2013: Energy and Sustainability 2013 Conference. Location: Bucharest, Romania. More info: http://www.wessex.ac.uk/13-conferences/ energy-and-sustainability-2013.html

4-7 July, 2013: ECSEE 2013 - The European Conference on Sustainability, Energy and the Environment Conference. Location: Brighton, United Kingdom. More info: http://ecsee.iafor.org/

14-18 July, 2013: World Renewable Energy CongressAustralia 2013. Location: Perth, Western Australia, Australia. More info: http://www.promaco.com.au/ events/WREC_2013/index.html 